\title{
OPPORTUNISTIC NECTAR-FEEDING BIRDS ARE EFFECTIVE POLLINATORS OF BIRD-FLOWERS FROM CANARY ISLANDS: EXPERIMENTAL EVIDENCE FROM ISOPLEXIS CANARIENSIS (SCROPHULARIACEAE) ${ }^{1}$
}

\author{
María C. Rodríguez-RodríGueZ² AND Alfredo Valido
}

Integrative Ecology Group, Estación Biológica de Doñana (CSIC), Avda. Ma Luisa s/n, Pabellón del Perú, 41013 Sevilla, Spain

\begin{abstract}
Insular floras, characterized by simple pollination networks, sometimes include novel mutualistic agents such as nonspecialist nectarivores. In this study we confirmed the effective pollination of Isoplexis canariensis by opportunistic nectar-feeding birds in Tenerife, Canary Islands, Spain. This plant is among the ornithophilous species of the Canarian flora that lack past and present specialist nectarivorous birds. Experimental hand pollinations revealed self-compatibility, but cross-pollinated flowers produced a greater percentage of viable seeds than self-pollinated ones. Flowers were visited by five species of birds (Phylloscopus canariensis, Parus caeruleus, Sylvia melanocephala, Serinus canarius, and Fringilla coelebs) and by the endemic lizard (Gallotia galloti, Lacertidae). Insect pollination was absent, and the few insect visitors acted as nectar thieves or secondary nectar robbers. Birds represented $93.1 \%$ of total visits, with the Canarian Chiffchaff, Ph. canariensis, being the most frequent visitor. Flowers visited by birds set more, larger, and heavier fruit than flowers from which birds were excluded. Bird visitation also enhanced seed viability. These results demonstrate the active role of these opportunistic birds as effective pollinators of this Canarian bird-flower species. Further, the results reveal the need to consider the effect of these birds on the evolution of ornithophilous floral traits in absence of specialist nectarivores.
\end{abstract}

Key words: Canary Islands; generalization; island ecology; Isoplexis; opportunistic passerine pollinators; ornithophily; Phylloscopus; pollination effectiveness; reproductive biology.

Compared to mainland systems, oceanic islands are generally characterized by simpler pollination networks (Olesen and Jordano, 2002; Dupont et al., 2003; Philipp et al., 2006) largely as a result of depauperate pollinator faunas (e.g., Carlquist, 1974; Barrett, 1998). Because of this, plant species are likely to include new, even novel flower-pollinator interactions after island colonization. For example, new insular interactions may include nontypical vertebrate pollinators such as opportunistic birds and lizards that visit flowers for nectar and/or pollen (e.g., Grant and Grant, 1981; Vogel et al., 1984; Olesen, 1985; Whitaker, 1987; Traveset and Sáez, 1997; Valido et al., 2002; Olesen and Valido, 2003a, b, 2004).

The occurrence of novel pollinator interactions on islands has been considered by Olesen and Valido (2003a, b, 2004) to be a product of "ecological release" (e.g., Terborgh and Faaborg, 1973; Cox and Ricklefs, 1977) in insular faunas. The logic is that the relative poverty of species on islands reduces their interspecific competition (Crowell, 1962; MacArthur

${ }^{1}$ Manuscript received 13 February 2008; revision accepted 3 September 2008.

The authors especially thank the municipal government of Buenavista del Norte and the Island Ecology and Biogeography Research Group (University of La Laguna) for providing housing during fieldwork. R. Pedrianes, D. Felipe, and forest guards of the Teno Rural Park helped during the fieldwork. The Department of Sustainability, Territory and Environment of the Insular Cabildo of Tenerife provided sampling permits that made this study possible. The authors thank M. Báez for identifying the Geometridae (Lepidoptera) and A. Martín and F. Valdés for technical support. Comments by P. Buston, P. Jordano, J. M. Olesen, E. W. Schupp, anonymous reviewers, and S. Balcomb, greatly improved the manuscript, especially the English. The study was supported by a fellowship from the Consejo Superior de Investigaciones Científicas (I3P-I3PPRE_06_00019 CSIC, Ministerio de Educación y Ciencia) to M.C.R., and a postdoctoral grant (I3P, CSIC) to A.V.

2 Author for correspondence (e-mail: canderguez@ebd.csic.es)

doi:10.3732/ajb.0800055 et al., 1972). This absence of competitors, together with reduced levels of predation and parasitism, induces some species to increase their abundance by "density compensation." This phenomenon was initially described for bird assemblages (Grant, 1966; MacArthur et al., 1972; Wright, 1980; Ricklefs and Miller, 1999) but has also been reported in insular lizard populations (Case et al., 1979; Rodda and Dean-Bradley, 2002). The high abundance of individuals within a species increases intraspecific competition and promotes the expansion of the trophic niche (e.g., Diamond, 1970; Keast, 1970; Alerstam et al., 1974; Cox and Ricklefs, 1977; Diamond and Marshall, 1977; Scott et al., 2003; Olesen and Valido, 2003a, b, 2004). Consistent with this idea, insular nectar-feeding birds tend to have greater population sizes, and they express higher levels of generalization in two ways. First, specialist nectar feeders on islands tend to visit more plant species compared to their mainland conspecifics or congeners (e.g., Linhart and Feinsinger, 1980; Feinsinger and Swarm, 1982). Second, opportunistic nectar feeders on islands tend to incorporate novel or rarely consumed food items such as floral rewards when other preferred resources (insects, fruits, and seeds) are scarce (Grant and Grant, 1981; Sakai et al., 1986; Werner and Sherry, 1987; Latta et al., 2001; Olesen and Valido, 2003b, 2004).

Opportunistic nectar-feeding passerine birds from the $\mathrm{Ca}$ nary Islands clearly illustrate these trends associated with ecological release, and they also have been regarded as critical for the reproduction and survival of plants they visit (Vogel et al., 1984; Olesen, 1985). In other words, these birds have been considered as potential effective pollinators that enhance plant fitness. This hypothesis, however, has not yet been tested, either in terms of pollinator quality (e.g., frequency of pollen deposition on stigmas, number of pollen grains delivered per visit and suitability of the pollen, and fruit/seed set; Herrera, 1987) or quantity (e.g., pollinator abundance and flower visitation rates; Herrera, 1989). 
In the Canary Islands, the endemic flora includes species of Canarina (Campanulaceae), Echium (Boraginaceae), Lavatera (Malvaceae), Lotus (Fabaceae), and Isoplexis (Scrophulariaceae), and their flower traits are related to the ornithophilous syndrome, including red-orange-yellow corolla colors, abundant dilute nectar, diurnal anthesis, and absent scent and landing platform (Proctor et al., 1996; Valido et al., 2004). Ancient members of Nectariniidae have been proposed as their extinct pollinators (Vogel et al., 1984; Olesen, 1985; Báez, 1992), but neither extant sunbirds, nor fossils of this group or other specialist nectarivores are present on these islands (e.g., Martín and Lorenzo, 2001). Specialist nectarivorous birds are also absent from adjacent southern Europe and northwestern Africa. The closest specialists are two nectarivorous sunbird species (Nectariniidae) from Israel and Palestine (Fry et al., 2000) and the recently reported hummingbird fossils from Central Europe (Germany, Mayr [2004]; SE France, Louchart et al. [2008]). Furthermore, the closest mainland relatives of these plant taxa have typical entomophilous floral traits and are most likely pollinated by insects in their natural areas (Lotus: Proctor et al., 1996; Ollerton and Lack, 1998; Lavatera: Fuertes-Aguilar et al., 2002; Digitalis: Sletvold, 2002; Grindeland et al., 2005; Echium: Klinkhamer and de Jong, 1990; Dupont and Skov, 2004). The one exception is Canarina, whose mainland representatives ( $C$. abyssinica Engler and $C$. eminii Ascherson ex Schweinf.) from the highlands of East Africa are visited and potentially pollinated by sunbirds (J. M. Olesen, University of Aarhus, personal communication). This mismatch between the presence of an insular ornithophilous flora and the absence of specialist nectarivores and mainland ornithophilous relatives represents a biological enigma in terms of both the origin and the maintenance of this bird-pollinated flora.

Several hypotheses have been formulated to explain the origin and maintenance of these ornithophilous floral traits: (1) Presumably extinct specialist nectarivorous birds on the islands exerted selective pressures on flowers, followed by their subsequent maintenance by opportunistic birds after disappearance of the specialists ("de novo specialist" hypothesis; Vogel et al., 1984; Olesen, 1985). (2) Selection by specialist birds took place on the mainland before the plant taxa reached the islands, after which the specialists were replaced by nonspecialized nectarivorous passerines ("relict" hypothesis; Valido et al., 2004). (3) Current opportunistic birds exerted phenotypic selection on flower traits on the islands ("de novo opportunist" hypothesis; Dupont et al., 2004; Valido et al., 2004). The absence of specialist nectarivorous birds in the insular fossil record weakens the first hypothesis, but supports the remaining two hypotheses (Valido et al., 2004). Under hypothesis 2, present-day opportunistic nectar feeding birds maintained pre-existing ornithophilous traits, while under hypothesis 3 , these traits evolved directly in response to pressures exerted by these opportunistic birds on the islands. Both hypotheses 2 and 3 rely on opportunistic nectar-feeding birds acting as effective pollinators. However, this role has not been documented to date despite the multiple studies of plant-vertebrate interactions on these islands over the past few decades (reviewed in Valido et al., 2004).

The objective of this study was to determine experimentally whether these passerine birds act as effective pollinators of one of the most predominant Canarian ornithophilous species, Isoplexis canariensis (L.) J. W. Loudon (Scrophulariaceae). We studied the breeding system of I. canariensis, identified all of its flower visitors, and investigated the pollination ability of bird visitors by taking into account the quantitative and qualitative components of this mutualistic interaction (sensu Herrera, 1987, 1989). For this purpose, we evaluated visitation frequency and the number of visited flowers (quantitative component) and measured fruit set and fruit size, as well as seed production and viability (qualitative component).

\section{MATERIALS AND METHODS}

Study area-The primary study site was located in the Teno Rural Park in NW Tenerife, Canary Islands, Spain. This area encompasses one of the oldest parts of the island, a 5.6-6.2 million-year-old basaltic massif (Guillou et al., 2004). Fieldwork was conducted from the end of May to the beginning of September 2006, covering the flowering and fruiting peaks of I. canariensis. The studied population was situated in the vicinity of Teno Alto at approximately $870 \mathrm{~m}$ a.s.1. The vegetation is a secondary laurel forest with Ilex canariensis Poiret (Aquifoliaceae), Erica arborea L. (Ericaceae), and Myrica faya Aiton (Myricaceae) as dominant tree species. Mean annual precipitation is over $350 \mathrm{~mm}$, with most of it falling between November and March. Annual average temperature is $19.4^{\circ} \mathrm{C}$, with January being the coldest month (Marzol-Jaén, 1984).

Study organisms - Isoplexis canariensis (Scrophulariaceae), locally known as cresta de gallo, is a Canarian endemic plant species. Three other endemic ornithophilous congeners from Macaronesian archipelagos exist: I. isabelliana (Webb \& Berthel.) Masf. and I. chalcantha Svent. \& O'Shan. from Gran Canaria and I. sceptrum (L. fil.) from Madeira. Together these four species represent a derived monophyletic group clearly separated from their closest relatives, the continental entomophilous foxgloves Digitalis (Bräuchler et al., 2004). Isoplexis canariensis is a perennial shrub, up to $2 \mathrm{~m}$ tall, with a candelabra-shaped growth (usually with $<6-7$ inflorescences, $N=55$ ). It grows mainly in the laurel forest in Tenerife, but has also been recorded in the recent past from La Gomera and La Palma (Bramwell and Bramwell, 1994).

Little is known of the reproductive biology of I. canariensis other than limited information on floral visitors (Vogel et al., 1984; Olesen, 1985; Valido et al., 2004), nectar volume and composition (Dupont et al., 2004; Valido et al., 2004), and pollen morphology (Pérez de Paz and Roca, 1982). The species has typical ornithophilous flowers, with large, orange, bilabiated corollas, no odor, and copious, dilute, and hexose-rich nectar (sucrose content $<33 \%$ ), all characteristics of opportunistic bird pollination (Faegri and van der Pij1, 1971; Dupont et al., 2004; Johnson and Nicolson, 2008). The blooming period is mostly May to August, but it is possible to find flowering individuals since December.

The hermaphroditic flowers are protandrous, $28.01 \pm 2.4 \mathrm{~mm}$ long and $22.6 \pm$ $2.7 \mathrm{~mm}$ wide $($ mean $\pm \mathrm{SD} ; N=40)$. They are borne in dense racemes, each of which produces on average $29.4 \pm 12.6$ flowers (mean $\pm \mathrm{SD} ; N=235$ ). From top to bottom, at any given time an inflorescence consists of a number of buds, several newly opened buds, male flowers, and female flowers followed by maturing seed capsules. Thus, individual flowers pass sequentially through male and female stages with little overlap, a mechanism that reduces geitonogamy. After fertilization, the ovary develops into a short, apiculate, and persistent capsule of 4.5-13.7 $\mathrm{mm}$ long and 2.6-8.3 $\mathrm{mm}$ wide $(N=286)$ and filled with hundreds of tiny cylindrical seeds (we have recorded up to 673 seeds in a capsule; see Results). These seeds are dispersed by gravity after capsule dehiscence. Introduced rats and moth caterpillars may act as fruit and seed predators.

Isoplexis canariensis flowers are visited primarily by Sylviidae birds (Phylloscopus, Sylvia), but also Paridae (Parus) and Fringillidae (Serinus, Fringilla) (Valido et al., 2004). All are opportunistic passerines consuming mainly arthropods, seeds, and fleshy fruits (Martín and Lorenzo, 2001). However, they have also been observed consuming nectar from many endemic plant species belonging to the Canarian bird-flower system, as well as several exotic garden plants (Vogel et al., 1984; Olesen, 1985; Valido et al., 2004; M. C. Rodríguez and A.Valido, personal observations). Flower visitation by endemic Canarian lizards (Gallotia galloti) has also been confirmed (Valido et al., 2004).

Breeding system of the plant-Hand-pollination experiments were conducted on 25 randomly chosen plants to determine the breeding system and the importance of opportunistic bird pollinators for reproduction. Basal, unpollinated flowers were emasculated and placed in muslin bags after pollination 
treatments to exclude any insects or potential windborne pollen grains. When stigmas were receptive, each plant received seven pollination treatments $(N=2$ flowers/treatment): (1) G1, geitonogamous crosses with pollen from the same inflorescence; (2) G2, geitonogamous crosses with pollen from a different inflorescence within the same plant; (3) A, autogamous crosses with self-pollen from the same flower; (4) X1, xenogamous crosses with pollen from other individuals in the same population; (5) X2, xenogamous crosses from individuals growing near the population but located $200 \mathrm{~m}$ away; and (6) X3, xenogamous crosses from individuals $>1000 \mathrm{~m}$ distance. Finally, we included (7) an apomictic treatment on emasculated and unpollinated flowers. A control group of untreated flowers was labeled and left open to natural pollination. Bags were removed when the perianth segments had dried. At the end of fruit ripening, the proportion of flowers that set fruit was calculated. To determine whether hand pollination treatments resulted in differences in female fitness, all fruits produced by each plant were collected before capsule dehiscence for laboratory measurements (fruit length, width, and mass) and for quantifying the percentage of viable and aborted seeds within each fruit. Seeds were considered aborted based on a characteristic darkness and smaller size; to assure this assumption, we selected 10 apparently viable and 10 apparently aborted seeds from each of 10 randomly selected individuals (total $N=100$ viable and 100 aborted seeds) and left them to germinate in darkness on wet filter paper in Petri dishes. None of the seeds initially scored as aborted germinated successfully compared to $83 \%$ of the seeds initially considered viable.

During fieldwork, several plants were infested by larvae of Gymnoscelis rufifasciata Haworth. (Lepidoptera: Geometridae). Oviposition (usually one egg) took place on immature flower buds and fruits, and the presence of the larva caused loss of both (M. C. Rodríguez, personal observation). These plants were excluded from hand pollination and exclusion experiments.

Flower visitors and visitation frequency - To identify flower visitors and determine their visitation frequency, 50 randomly selected plants were monitored during focal watches at comparable stages of flowering (total observation period $=725 \mathrm{~h}$ ). All observations were made between 14 June and 25 August 2006, spanning the whole flowering season of the population. Each plant was observed for 30-min censuses ( $N=29$ censuses/plant) from 0700 to 2130 hours, divided into three periods (morning, afternoon, and evening). In each census, we recorded visits by birds and lizards. Vertebrates were observed from a point located 7-10 m away from the focal plant with the observer hidden in a shrub and using binoculars. For each visit, we recorded the species, sex, and age (juvenile vs. mature) of flower visitors whenever possible, as well as their foraging behavior (i.e., whether they visited flowers legitimately, perching, or hovering). Separate 30-min censuses were also conducted on each plant to record visitation by insects; methods were the same as for vertebrates except that observations were conducted $1-2 \mathrm{~m}$ from the focal plant. In addition, apart from census periods, we paid special attention to visits by potential insect pollinators (e.g., Bombus) when they were flying around. Due to the lack of insect visits, these censuses were excluded from analysis. We did not search for nocturnal pollinators, but their probable absence is supported by our results (see Relative effectiveness of birds as pollinators in Results).

Relative effectiveness of birds as pollinators-Based on our observations of flower visitors, we conducted field experiments to investigate the pollination role of the principal visitors (passerine birds) of I. canariensis. We selectively excluded vertebrate visitors from 30 individuals of similar size (with $\geq 5$ inflorescences) that were not used in the censuses or hand pollinations. The experiment had four exclusion treatments, all performed on each plant and randomly assigned to a different inflorescence within each plant. On each inflorescence, we marked 10 basal flowers still in bud stage $(N=10$ replicates/treatment/plant $)$ and applied one of the following treatments: (1) All visitors treatment, the control treatment with open-pollinated flowers visited by both birds and lizards; (2) Only birds treatment, with flowers visited only by birds, with lizards excluded by a $25-\mathrm{cm}$ diameter cardboard funnel covered with plastic at the base of inflorescences; (3) Spontaneous autogamy treatment, with unopened buds enclosed in muslin bags (to exclude any flower visitors or windborne pollen) to check for spontaneous self-pollination; and (4) No visitors treatment, in which total exclusion to vertebrates was ensured by the simultaneous combination of the basal cardboard funnel and a $50 \times 50 \mathrm{~cm}$ cage (with holes of $2.2 \mathrm{~cm}$ in diameter) surrounding the inflorescence. The large cage size prevented birds from accessing the inflorescence from the outside of the cage.

In treatments 2 and 4 , flowers were emasculated by removing the stamens from all the buds prior to anthesis. For both treatments, because lizards climb the stem to reach flowers, the funnel was placed on erect inflorescences not in contact with the surrounding vegetation that could provide alternative floral access; the lowermost part of the funnel was completely adjusted to fit the inflorescence stem diameter, so funnels represented an obstacle for climbing of lizards; for treatment 2, we left a reasonable distance between the uppermost extreme of the funnel and the basal flowers to let passerines perch. The experiments were inspected daily to ensure that the exclusions did not affect the normal foraging of flower visitors. After fruit ripening from August through September 2006, we scored the total number of fruits produced per treatment and collected them to evaluate differences in fruit measurements and fruit set, as well as the percentage of viable seeds per fruit.

Data analysis-We used a type III sums of squares (SS) one-way ANOVA (GLM procedure in SPSS v.11; SPSS Inc., Chicago, Illinois, USA) followed by a Tukey test of multiple comparisons. Each estimate of plant reproductive success (fruit size, fruit set, percentage of viable seeds per ripe fruit) was analyzed separately as a dependent variable. Treatments were used as fixed effects to test differences among treatments. The individual plant was used as random effect to control for lack of independence among flowers on the same individual plant. Logarithmic and arcsine transformations were used to normalize data before analyses (Sokal and Rohlf, 1995). Throughout the paper, all means are accompanied with their standard deviation unless otherwise indicated.

\section{RESULTS}

Breeding system-All flowers in the self- (geitonogamous and autogamous) and cross- (xenogamous) hand pollination treatments produced fruits (100\% fruit set in each treatment). In contrast, the apomictic treatment had considerably lower fruit set (only $18 \%$ of flowers produced fruits, $N=50$ ), and none of the apomictically produced fruits had viable or aborted seeds inside; they were therefore excluded from analysis. Self- and cross-pollen produced fruits were of similar size (Tukey test; $P>0.005$ for all size variables; $\log$ transformed). However, the percentage of viable seeds per fruit was significantly affected by the pollen source $\left(F_{6,168}=17.9, P<0.001\right.$, arcsine transformed; Fig. 1). The three xenogamous crosses produced higher values (for the intrapopulation level [X1], $97.6 \pm 2.6 \%$ viable seeds.fruit ${ }^{-1} ; 200 \mathrm{~m}$ distance [X2], $98.1 \pm 1.6 \%$; and for $>1000 \mathrm{~m}$ [X3], 97.2 $\pm 3.8 \%$ ) than did the autogamous ([A], $85.8 \pm 17.3 \%]$ and geitonogamous crosses (from the same inflorescence [G1], $81.5 \pm 24.5 \%$; from a different inflorescence [G2], $82.2 \pm$ $22.8 \%)$, and similar to control fruits $(93.3 \pm 9.5 \%)$ (Tukey test; Fig. 1). There was no effect of pollen source distance on seed production for the three xenogamous treatments (Tukey test; $P>0.05)$.

Quantitative importance of flower visitors-The observed flower visitors comprised five species of passerines (the Canarian endemism Phylloscopus canariensis Hartwig and the native birds Sylvia melanocephala Gmelin, Parus caeruleus L., Serinus canarius L., and Fringilla coelebs L.), as well as the endemic Canarian lacertid Gallotia galloti Oudart. Outside census periods, one individual of the introduced mouse Mus musculus L. was observed visiting one flower for nectar but from an inflorescence very close to the ground. This observation can be considered as very sporadic. No pollinating insect visitors were recorded either during specific census periods or outside censuses. Several ants (Hymenoptera, Formicidae) and Lassioglosum bees (Halictidae) were seen in mature flowers thieving nectar or behaving as secondary nectar robbers, but they never contacted reproductive organs. Individuals of Calliphora sp. (Diptera) fed on nectar that fell on the surface of leaves when the inflorescence was shaken by frequent wind. On six occasions, endemic bumblebees (Bombus canariensis Pérez) attempted to land on corollas but failed and after a few seconds they switched 


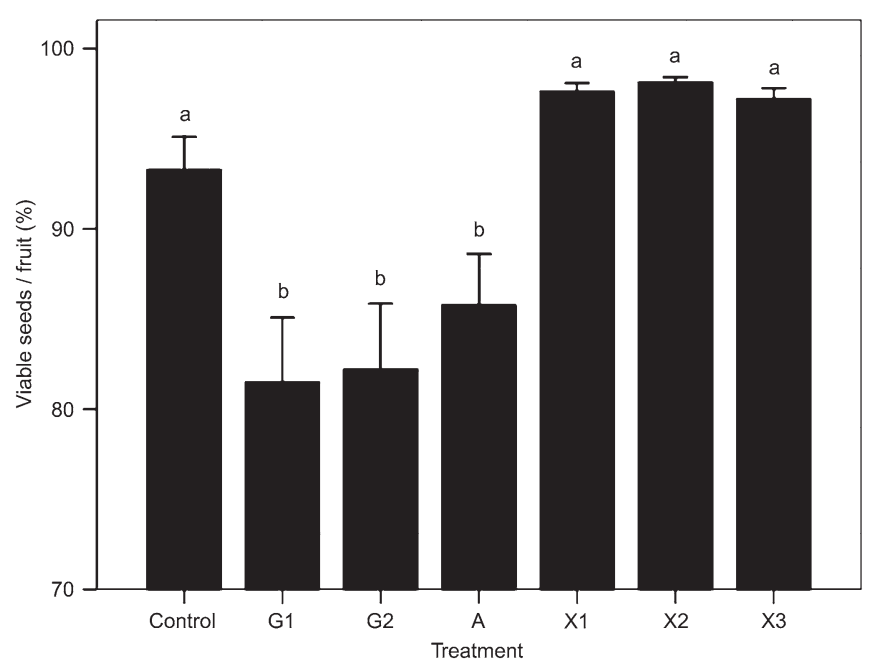

Fig. 1. Percentage of viable seeds per fruit (no. of viable seeds/total no. of seeds within each fruit) resulting from experimental hand pollination treatments $\left(N=50\right.$ fruits.treatment $\left.{ }^{-1}\right)$. Treatments G1 and G2 correspond with geitonogamous, A with autogamous, and $\times 1, \times 2$, and $\times 3$ with xenogamous crosses (see Material and Methods for details). Letters indicate significant differences among treatments using Tukey's test after one-way ANOVA (logarithmic transformation) and using a GLM procedure. Data are means $\pm 1 \mathrm{SE}$.

to adjacent coflowering species, e.g., Cistus monspeliensis L. (Cistaceae) and Ilex canariensis Poir. (Aquifoliaceae). Thus, vertebrates are the only flower visitors acting as potential pollinators.

Of 522 observed potential pollination visits, birds made $93.1 \%(N=486)$ and lizards $6.9 \%(N=36)$. Birds visited on average 17 times as often as did lizards $(0.34 \pm 0.76$ visits $\cdot 30$ $\mathrm{min}^{-1}$. plant ${ }^{-1}$ and $0.02 \pm 0.24$ visits. $30 \mathrm{~min}^{-1}$. plant $^{-1}$, respectively) and approximately 14 times more total flowers than did lizards (birds, $N=1349$ flowers; lizards $=95$ ). The endemic $P h$. canariensis was the most frequent visitor $(83.3 \%$ of recorded floral visits, Table 1). It showed intensive aggression against conspecifics and to a lesser degree against other bird species such as $\mathrm{Pa}$. caeruleus. The lizard $\mathrm{G}$. galloti was the second most common visitor $(6.9 \%)$, followed by the other four passerines: $\mathrm{Pa}$. caeruleus (5.8\%), Sy. melanocephala (3.1\%), Se. canarius $(0.8 \%)$, and F. coelebs $(0.2 \%)$. Almost all visits were legitimate, and other than $S e$. canarius, the nectar gathering behavior of the species was quite similar. The visitor either landed on (birds) or climbed (lizards) an inflorescence and visited one of the flowers or a flower on an adjacent inflorescence, rapidly introducing its head into the bilabiated corolla to reach the nectar. In this way, the head of both lizards and birds contacted both the stigma and anthers located in the uppermost part of corolla; thus, pollen grains were most often deposited on the head where they were available to be transferred to the stigmas of subsequently visited flowers. All bird species perched on the main stem just below the basal flowers when visiting inflorescences, but $P h$. canariensis also obtained nectar by hovering or using a combination of both strategies. The birds also searched for small arthropods between flowers and along the inflorescence stalk. The canary, Se. canarius, was the only frequent nectar robber among the birds. It perched at the top of the inflorescences and pierced (sometimes partly destroying or tearing apart) the base of the corolla where nectaries are located, or it probed previously made nectar-robbing holes. Thus, virtually none of its visits likely resulted in successful pollination; all 26 flowers visited by Se. canarius during censuses were nectar robbed, but some legitimate visits were observed outside census periods. Parus caeruleus also committed nectar robbery, but this behavior was observed only once in 30 recorded visits. On the other hand, all lizard visits were potentially legitimate.

The Isoplexis blooming coincided with the reproductive period of these birds. Mixed flocks of adult and juvenile $\mathrm{Ph}$. $\mathrm{Ca}$ nariensis and $\mathrm{Pa}$. caeruleus moved around the area frequently, and individuals of family groups fed in the same plant at once. Juveniles constituted $63-70 \%$ of the visitors in Pa. caeruleus, Sy. melanocephala and G. galloti. All recorded individuals of Serinus and Fringilla were solitary juveniles. This figure could not be estimated for $\mathrm{Ph}$. canariensis because of the similar plumage appearance between immatures and adults.

Bird visitation persisted throughout the day regardless of the weather. It increased during the day and peaked at 1700-1900 hours, whereas lizards showed the highest visitation activity between 1300 and 1500 hours. No lizard feeding bouts were observed in morning or evening periods (Fig. 2).

Relative effectiveness of birds as pollinators-During the censuses, frequent observations were made of birds entering flowers of the All visitors and Only birds treatments, while no pollinators (including insects) were seen entering flowers in the No visitors treatment, confirming the effectiveness of the experimental manipulations and enclosures. Significant differences were found among all the exclusion treatments in fruit biometric measurements (Table 2). The largest fruits were those produced by All visitors and Only birds treatments, with size and mass decreasing in the Spontaneous autogamy and finally

TABLE 1. Number of visits, percentage of flowers visited ( $N=1444$ flowers), and visitation for each vertebrate species (birds and lizards) observed visiting Isoplexis canariensis. $N=50$ plants observed in 29 periods of 30-min throughout the day (morning: 700-1130 hours; afternoon: 1130-1800 hours; evening: $1800-2130$ hours) for a total of $725 \mathrm{~h}$ of observation. Data are means \pm SD.

\begin{tabular}{|c|c|c|c|c|c|c|}
\hline \multirow[b]{2}{*}{ Visitor species } & & \multirow[b]{2}{*}{ No. of visits } & \multirow[b]{2}{*}{ Flowers $(\%)$} & \multicolumn{3}{|c|}{ Visitation rate (no. visits $30 \mathrm{~min}^{-1} \cdot$ plant $^{-1}$ ) } \\
\hline & & & & Morning & Afternoon & Evening \\
\hline \multirow[t]{5}{*}{ Birds } & Phylloscopus canariensis & 435 & 84.3 & $0.21 \pm 0.53$ & $0.36 \pm 0.83$ & $0.29 \pm 0.69$ \\
\hline & Parus caeruleus & 30 & 4.01 & $0.02 \pm 0.14$ & $0.02 \pm 0.17$ & $0.03 \pm 0.16$ \\
\hline & Sylvia melanocephala & 16 & 3.4 & $0.01 \pm 0.11$ & - & $0.03 \pm 0.18$ \\
\hline & Serinus canarius & 4 & 1.8 & - & $0.00 \pm 0.06$ & $0.01 \pm 0.08$ \\
\hline & Fringilla coelebs & 1 & 0.1 & $0.00 \pm 0.05$ & - & - \\
\hline Total birds & & 486 & 93.4 & $0.24 \pm 0.56$ & $0.39 \pm 0.89$ & $0.35 \pm 0.74$ \\
\hline Lizard & Gallotia galloti & 36 & 6.6 & - & $0.06 \pm 0.36$ & - \\
\hline Total & & 522 & & & & \\
\hline
\end{tabular}




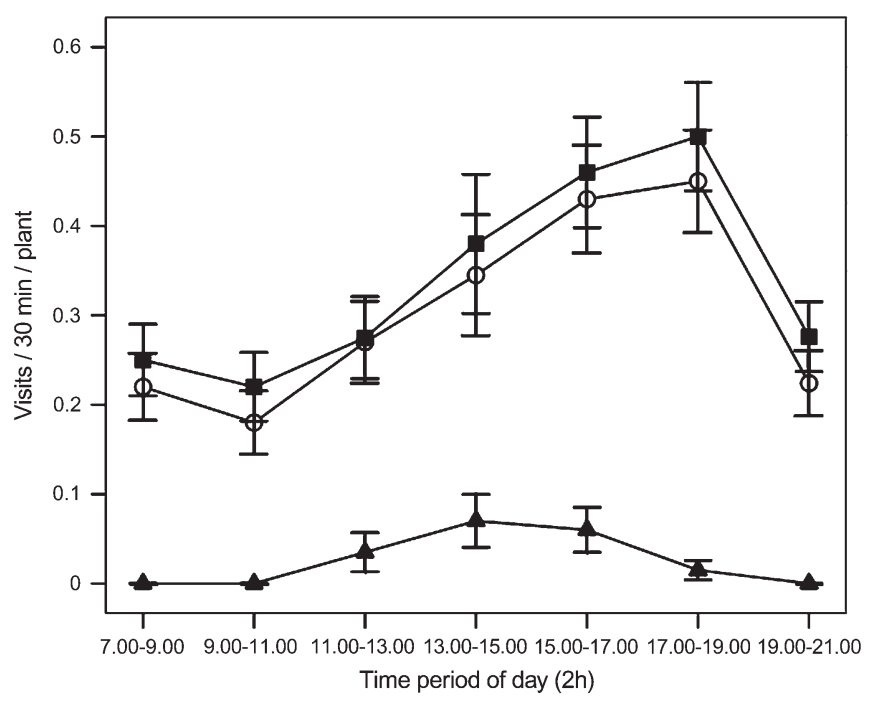

Fig. 2. Temporal variation in the visitation rate of flower visitors of Isoplexis canariensis throughout the day performed by all birds ( $\square$ ), and the two more frequent visitors, Phylloscopus canariensis $(\bigcirc)$ and Gallotia galloti $(\mathbf{\Delta})$. Visitation rate is represented by the mean number of visits.30 $\mathrm{min}^{-1}$. plant ${ }^{-1}$ in 2-h periods from dawn to dusk. Data are means $\pm 1 \mathrm{SE}$.

in the No visitors treatments (Tukey test; $P<0.001$ for all size variables; log transformed; Table 2). Flowers in the All visitors and Only birds treatments also set significantly more fruits than the Spontaneous autogamy and No visitors treatments $\left(F_{3,116}=\right.$ 39.8, $P<0.001$; arcsine transformed; Fig. 3). Inflorescences accessible to birds (All visitors and Only birds treatments) always had $>85 \%$ fruit set, whereas those from which birds were excluded had $62.3 \pm 26.2 \%$ (Spontaneous autogamy treatment) and $31.3 \pm 40.2 \%$ (No visitors treatment) fruit set on average (Fig. 3).

In accordance with results of the apomictic pollination treatment, most of fruits from the No visitors treatment were empty (93.6\% fruits without seeds, $N=94)$. Although a few fruits in this treatment produced seeds $(10 \pm 5.8$ seeds [i.e., viable and aborted combined].fruit ${ }^{-1} ; N=6$ ), this could have been due to inadvertent pollen contamination when the stamens were removed. The mean value of seed production was practically zero $\left(0.6 \pm 2.8\right.$ seeds.fruit $\left.{ }^{-1} ; N=94\right)$ and therefore excluded from subsequent analysis.

Fruits from the Only birds and All visitors treatments produced a higher percentage of viable seeds per fruit than those from the Spontaneous autogamy treatment (All visitors $=88.8$ $\pm 21.5 \%$ viable seeds $\cdot$ capsule $^{-1}$; Only birds $=87.1 \pm 28.1 \%$; Spontaneous autogamy $=40.9 \pm 38.1 \% ; F_{2,87}=77.1, P<0.001$; Tukey test; arcsine transformed; Fig. 4).

\section{DISCUSSION}

Despite multiple reports during the past few decades documenting a high frequency of passerine birds as flower visitors of Canarian ornithophilous flora (reviewed in Valido et al., 2004), no previous study has tested whether these opportunistic nectarfeeding vertebrates act as effective pollinators. Previous work (Vogel et al., 1984; Olesen, 1985) considered these plants as ornithophilous "widow" species that had incorporated passerine birds as suboptimal pollinators after the hypothetical insular disappearance of specialist nectarivores. Our present report constitutes the first experimental evidence that these passerines are indeed effective pollinators of the Canarian endemic Isoplexis canariensis and thus may act as selective agents on ornithophilous traits such as flower color and nectar composition for a number of Canary Islands species (e.g., Dupont et al., 2004).

Flower visitors - Vertebrates were the only flower visitors acting as legitimate pollinators of I. canariensis. Birds were more important than lizards in terms of both the total number of visits and visited flowers (Table 1). The analysis of the quantitative and qualitative components of pollination effectiveness confirmed that $I$. canariensis depends on these opportunistic passerines for successful reproduction. The incidence of insect visitors was marginal, with the few taxonomic groups involved acting as nectar thieves or secondary nectar robbers. Even the endemic Canarian bumblebee Bombus canariensis bypassed Isoplexis flowers despite the bee's high relative abundance in the study area. The absence of entomophilous pollination interactions in our study area is consistent with observations of other populations of $I$. $\mathrm{Ca}$ nariensis in Tenerife, and also for the closely related species from Gran Canaria (I. isabelliana, I. chalcantha) (Valido et al., 2004; A. Valido personal observation; J. M. Olesen and L. Chittka, University of Aarhus and Queen Mary University of London, respectively, personal communications). The dilute, hexose-rich nectar (Dupont et al., 2004) and the absence of UV reflectance of Isoplexis flowers (Olesen, 1985; A. Valido, unpublished data) likely explain their low attractiveness to bees because bumblebees may prefer sucrose-rich nectar of intermediate concentration (Baker and Baker, 1990) and their photoreceptor spectral sensitivity peaks in the UV range (Briscoe and Chittka, 2001).

Although I. canariensis was visited by five species of passerine birds, Phylloscopus canariensis was undoubtedly the most important from a quantitative point of view. Curiously, this endemic bird has been recorded visiting more ornithophilous plant species than any other passerine in the Canary Islands (up to 11 plant species; Valido et al., 2004; M. C. Rodríguez and A. Valido, personal observations; F. Siverio, Alas Cinematografía, personal communication). It also represents a clear example of "density compensation" on this archipelago, with the highest bird population densities of the Canarian passerines. For example, in the laurel forest it is the

TABLE 2. Biometry of the fruits (length, width, and mass) obtained in the exclusion treatments (All visitors, $N=286$ fruits; Only birds, $\mathrm{N}=268$; Spontaneous autogamy, $N=187$; No visitors, $N=94$ ). Significant differences were found among all treatments for each fruit trait (Tukey test after oneway ANOVA and using a GLM procedure; logarithmic transformation; $\mathrm{df}=3,116$ for each variable). Different letters indicate significant differences among treatments. Data are means $\pm \mathrm{SD}$. $* * * P<0.001$.

\begin{tabular}{|c|c|c|c|c|c|c|}
\hline \multirow[b]{2}{*}{ Variable } & \multicolumn{4}{|c|}{ Exclusion treatment } & \multicolumn{2}{|c|}{ ANOVA } \\
\hline & All visitors & Only birds & Spontaneous autogamy & No visitors & $F$ & $P$ \\
\hline Length (mm) & $10.1 \pm 1.3 \mathrm{a}$ & $9.7 \pm 1.4 b$ & $8.2 \pm 1.6 \mathrm{c}$ & $7.6 \pm 0.9 \mathrm{~d}$ & 41.3 & $* * *$ \\
\hline Width (mm) & $6.5 \pm 0.9 \mathrm{a}$ & $6.2 \pm 1.1 \mathrm{~b}$ & $5.2 \pm 1.1 \mathrm{c}$ & $4.6 \pm 0.5 \mathrm{~d}$ & 43.4 & $* * *$ \\
\hline Mass (mg) & $80.7 \pm 29.8 \mathrm{a}$ & $70.7 \pm 29.1 \mathrm{~b}$ & $38.4 \pm 23 \mathrm{c}$ & $21.5 \pm 4.7 \mathrm{~d}$ & 48.1 & $* * *$ \\
\hline
\end{tabular}




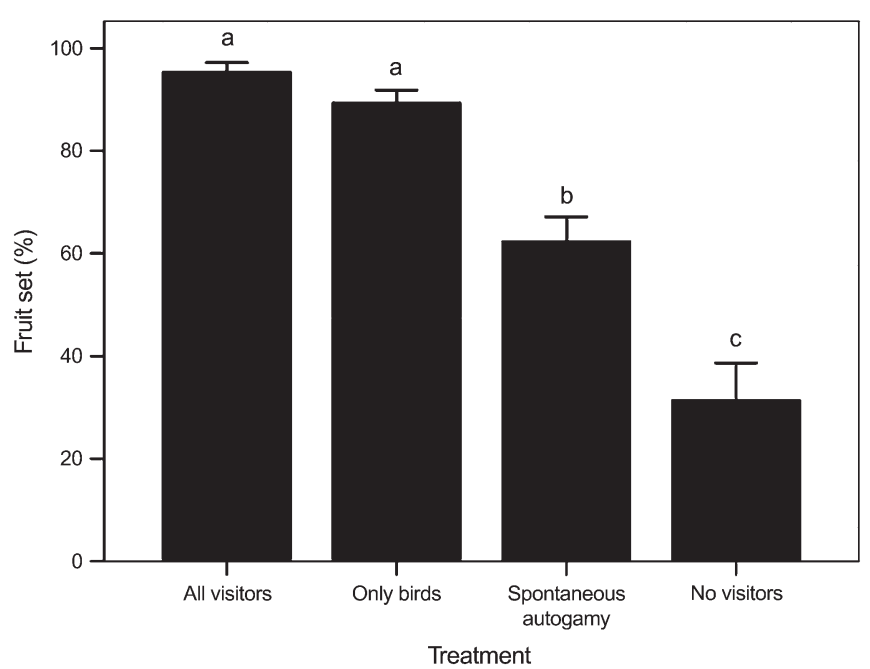

Fig. 3. Percentage of fruit set (no. of fruits produced/no. of flowers) produced in the exclusion treatments (All visitors, $N=286$ fruits; Only birds, $N=268$; Spontaneous autogamy, $N=187$; No visitors, $N=94$ ). Letters indicate significant differences among treatments using Tukey's test after one-way ANOVA (arcsine transformation). Data are means \pm 1 SE.

most abundant bird and has been recorded at densities as high as 41.1 birds $\cdot 10$ ha $^{-1}$ (Valido and Delgado, 1996). In addition, the peak flowering period of Isoplexis coincides with the minimum availability of arthropods (and fleshy fruits) within the laurel forest (Valido and Delgado, 1996). Thus, "density compensation" and the matching of peak flowering with the period of food scarcity appear to combine to enhance this novel vertebrate pollinator-plant interaction, based on the use of nectar as an important alternative food resource.

Pollination effectiveness-Experimental manipulations to measure the relative effectiveness of birds also highlight the asymmetrical contribution of birds to the reproductive success of I. canariensis compared to lizards. Inflorescences visited only by birds produced more, larger, and heavier fruits than did those from which birds were excluded (Table 2). The absence of clear differences in fruit set and percentage of viable seeds per fruit between the All visitors and Only birds exclusion treatments suggests that birds provide the majority of the pollination service (Figs. 3, 4). In addition, these opportunistic passerines may enhance female fecundity through effective pollen flow because bird-pollinated inflorescences had a higher percentage of viable seeds per fruit than did self-pollinated inflorescences (Fig. 4). These results suggest that birds may promote more xenogamous than geitonogamous or autogamous crosses, despite I. canariensis' large floral display, which at first may seem to promote selfing. In support of this expectation, the low number of Isoplexis flowers within individual plants that are visited by $P h$. canariensis on a single visit $\left(2.9 \pm 2.43\right.$ flowers $^{\text {plant }}{ }^{-1}$; $N=435$ ) suggests they are likely to effect cross-pollination. These results agree with those from the hand pollination experiments, in which the production of fruits and viable seeds was significantly higher after outcrossing (Fig. 1).

Although lizards visited flowers at the second highest rate (Table 1), there were no differences in any fitness variables between All visitors and Only birds treatments. This would seem to indicate that lizards play a minor role in the reproduction of this species. However, our exclusion experiment did not include

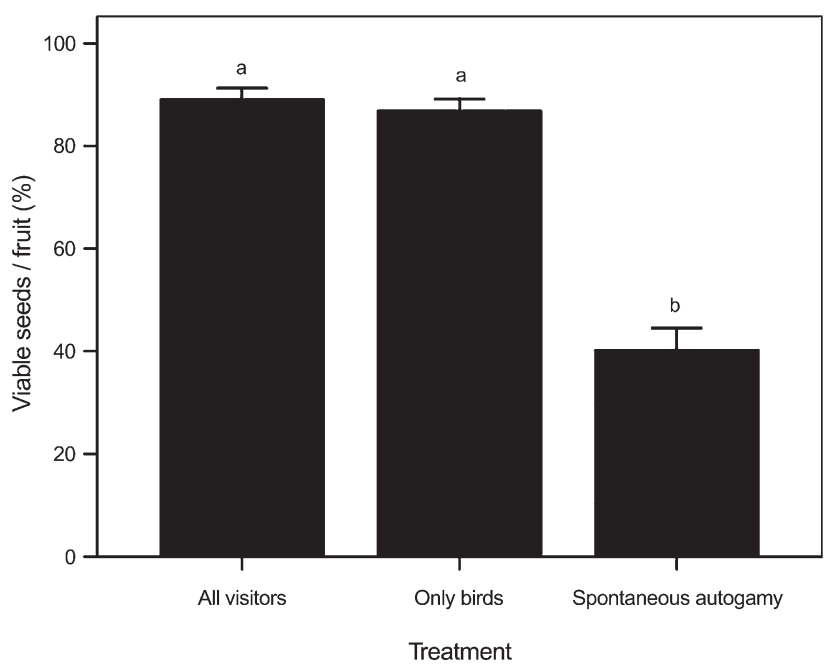

Fig. 4. Percentage of viable seeds per fruit (no. of viable seeds/total no. of seeds within each fruit) in exclusion treatments (All visitors, $N=286$ fruits; Only birds, $N=268$; Spontaneous autogamy, $N=187$ ). Letters indicate significant differences among treatments using Tukey's test after oneway ANOVA (arcsin transformation) and using a GLM procedure. Data are means $\pm 1 \mathrm{SE}$.

an Only lizards treatment to support this conclusion. Besides, this study only takes into account the maternal component of fitness and thus our results provide just a partial approximation of pollination effectiveness. We have no data on male fitness components such as pollen removal, transfer, and donation, which may provide additional information on plant reproductive success. In addition, these two groups of pollinators differ in their pollinator behavior (e.g., capacity of movement), which may affect the dynamics of pollen transfer within and between plants (Levin, 1981; Price and Waser, 1982; Thomson et al., 1986; Kearns and Inouye, 1993) and, consequently, the relative probability of outcrossing. Bird and lizard species may also differ in the quantity and quality of the pollen loads they deliver, which could affect seed production and the quality of the progeny, among other fitness components.

Evolution of ornithophily in Isoplexis - Assessing pollination effectiveness and finding possible differences among pollinators constitutes the first step in research on the potential role of pollinators on the maintenance of plant populations and also on the evolution of flower traits. Although we can say that opportunistic bird pollinators play a role in the maintenance of the Isoplexis populations on the Canary Islands, a solution to the origin of its ornithophily is not clear. Members of this genus show distinctive characters such as woodiness and ornithophily; traits that have been traditionally considered to be plesiomorphic and indicative of an ancient lineage that survived the severe climatic conditions occurring in the Quaternary on the mainland (e.g., Bramwell, 1972; Vogel et al., 1984; Olesen, 1985). However, recent molecular data suggest that Isoplexis is derived from herbaceous continental Digitalis species (Bräuchler et al., 2004). Currently, all Digitalis species are pollinated by insects (principally bumblebees), indicating that a pollinator shift had to occur at some point during the evolutionary transition from entomophilous on the mainland to ornithophilous on islands. Isoplexis flowers could have evolved in continental predecessors with selection exerted by specialist nectarivores, 
prior to arrival in the islands ("relict" hypothesis) or exclusively after island colonization ("de novo opportunistic" hypothesis). Interestingly, Dupont et al. (2004) provided clear evidence of evolutionary changes in floral traits (nectar sugar composition) in seven Canarian plant lineages compared to their entomophilous mainland relatives. In particular, they found a consistent association of hexose nectar with ornithophily and sucrose nectar with entomophily. Consequently, nectar sugar chemistry in these lineages seems to have evolved readily on islands, perhaps even in response to pollination by opportunistic passerines.

However, it is not completely clear that Digitalis was only bee-pollinated throughout its evolutionary history. For example, the discovery of hummingbird fossils in Europe (Mayr, 2004; Louchart et al., 2008), the existence of some characteristics associated with bird visits (orange-yellow flowers) in the closest relative D. obscura (Bräuchler et al., 2004), and the observation that Digitalis sucrose nectar is a preferred food resource for hummingbirds (David, 1996) and sunbirds (Fry et al., 2000) when these plants are introduced in northwestern America and South Africa, all leave open the possibility that the pollination of the Digitalis-Isoplexis ancestor was assisted by specialist nectarivorous birds on the mainland. Thus, evidence supports both the "relict" and "de novo opportunistic" hypotheses and we cannot refute either one at this time.

Conclusion-Based on our results, opportunist nectar-feeding birds are effective pollinators of $I$. canariensis. The quantity and quality components of this mutualistic interaction resulted in positive consequences for female plant fitness by enhancing fruit production and seed viability. These results indicates that opportunistic nectar feeding birds play a role in the current maintenance of plant populations and possibly in the future evolution of some flower traits. Still, we are able to say little about whether opportunistic or specialist nectar feeders played a role in the origin of ornithophily. The next step should be to examine the variation between mutualists in the strength of their interactions with the plant, either at the specific level or the functional level (birds vs. lizards). To achieve an accurate assessment of pollinator effectiveness, one would also need to analyze differences in male fitness and pollen transfer, as affected by the different pollinator's behavior and, from an evolutionary perspective, to analyze their potential to select for ornithophilous floral traits.

\section{LITERATURE CITED}

Alerstam, T., S. G. Nilsson, and S. Ulfstrand. 1974. Niche differentiation during winter in woodland birds in southern Sweden and the island of Gotland. Oikos 25: 321-330.

BÁEZ, M. 1992. Zoogeography and evolution of the avifauna of the Canary Islands. In K. E. Campbell [ed.], Papers in avian paleontology, 424-431. Natural History Museum of Los Angeles County, Los Angeles, California, USA.

BAKER, H. G., AND I. BAKER. 1990. The predictive value of nectar chemistry to the recognition of pollinator types. Israel Journal of Botany 39: $157-166$.

BARRETT, S. C. H. 1998. The reproduction biology and genetic of island plants. In P. R. Grant [ed.], Evolution on islands, 18-34. Oxford University Press, Oxford, UK.

Bramwell, D. 1972. Endemism in the flora of the Canary Islands. In D. H. Valentine [ed.], Taxonomy, phytogeography and evolution, 141-159. Academic Press, London, UK .

Bramwell, D., and Z. I. Bramwell. 1994. Flores silvestres de las Islas Canarias. Editorial Rueda, Madrid, Spain.

Bräuchler, C., H. Meimberg, and G. Heubl. 2004. Molecular phylogeny of the genera Digitalis L. and Isoplexis (Lindley) Loudon
(Veronicaceae) based on ITS- and trnL-F sequences. Plant Systematics and Evolution 248: 111-128.

Briscoe, A. D., AND L. ChitTKa. 2001. The evolution of color vision in insects. Annual Review of Entomology 46: 471-510.

Carlquist, S. 1974. Island biology. Columbia University Press, New York, New York, USA.

Case, T. J., M. E. Gilpin, and J. M. Diamond. 1979. Overexploitation, interference competition, and excess density compensation in insular faunas. American Naturalist 113: 843-854.

Cox, G. W., AND R. E. RICKLEFs. 1977. Species diversity and ecological release in Caribbean land bird fauna. Oikos 28: 113-122.

Crowell, K. L. 1962. Reduced interspecific competition among birds of Bermuda. Ecology 43: 75-88.

DAvid, S. 1996. Wildlife in my backyard. Part 3a: Attracting hummingbirds. Blue Bill 43: 15-24.

DiAmond, J. M. 1970. Ecological consequences of island colonization by southwest Pacific birds. I. Types of niche shifts. Proceedings of the National Academy of Sciences, USA 67: 529-536.

Diamond, J. M., and A. G. Marshall. 1977. Niche shifts in New Hebridean birds. Emu 77: 61-72.

Dupont, Y. L., D. M. Hansen, And J. M. Olesen. 2003. Structure of a plant-flower-visitor network in the high-altitude sub-alpine desert of Tenerife, Canary Islands. Ecography 26: 301-310.

Dupont, Y. L., D. M. Hansen, J. T. Rasmussen, and J. M. Olesen. 2004. Evolutionary changes in nectar sugar composition associated with switches between bird and insect pollination: The Canarian bird-flower element revisited. Functional Ecology 18: 670-676.

Dupont, Y. L., AND C. SKov. 2004. Influence of geographical distribution and floral traits on species richness of bees (Hymenoptera: Apoidea) visiting Echium species (Boraginaceae) of the Canary Islands. International Journal of Plant Sciences 165: 377-386.

FAegri, K., AND L. VAN DER PIJL. 1971. The principles of pollination ecology. Pergamon Press, Oxford, UK.

Feinsinger, P., AND L. A. Swarm. 1982. "Ecological Release", seasonal variation in food supply, and the hummingbird Amazilia tobaci on Trinidad and Tobago. Ecology 63: 1574-1587.

Fry, C. H., S. Keith, and E. K. Urban. 2000. The birds of Africa, vol VI. Academic Press, London, UK.

Fuertes-Aguilar, J., M. F. Ray, J. Francisco-Ortega, A. SantosGuerra, AND R. K. JANSEN. 2002. Molecular evidence from chloroplast and nuclear markers for multiple colonizations of Lavatera (Malvaceae) in the Canary Islands. Systematic Botany 27: 74-83.

Grant, B. R. 1966. A systematic study of the territorial birds of the Tres Marías Islands in Mexico. I. Numbers and biomass. Canadian Journal of Zoology 44: 805-815.

Grant, B. R., ANd P. R. Grant. 1981. Exploitation of Opuntia cactus by birds on the Galápagos. Oecologia 49: 179-187.

Grindeland, J. M., N. SLetvold, AND R. A. Ims. 2005. Effects of floral display size and plant density on pollinator visitation rate in a natural population of Digitalis purpurea. Functional Ecology 19: 383-390.

Guillou, H., J. C. Carracedo, R. Paris, and F. J. P. Torrado. 2004. Implications for the early shield-stage evolution of Tenerife from K/Ar ages and magnetic stratigraphy. Earth and Planetary Science Letters 222: 599-614.

Herrera, C. M. 1987. Components of pollinator "quality": Comparative analysis of a diverse insect assemblage. Oikos 50: 79-90.

Herrera, C. M. 1989. Pollinator abundance, morphology, and flower visitation rate: Analysis of the "quantity" component in a plant-pollinator system. Oecologia 80: 241-248.

Johnson, S. D., AND S. W. Nicolson. 2008. Evolutionary associations between nectar properties and specificity in bird pollination systems. Biology Letters 4: 49-52.

Kearns, C. A., And D. W. Inouye. 1993. Techniques for pollination biologists. University Press of Colorado, Niwot, Colorado, USA.

Keast, A. 1970. Adaptive evolution and shifts in niche occupation in island birds. Biotropica 2: 61-75.

KlinkHamer, P. G. L., AND T. J. DE Jong. 1990. Effects of plant size, plant density and sex differential nectar reward on pollinator visitation in the protandrous Echium vulgare (Boraginaceae). Oikos 57: 399-405. 
Latta, S. C., H. A. Gamper, and J. R. Tietz. 2001. Revising the convergence hypothesis of avian use of honeydew: Evidence from Dominican subtropical dry forest. Oikos 93: 250-259.

Levin, D. A. 1981. Dispersal versus gene flow in plants. Annals of the Missouri Botanical Garden 68: 233-253.

Linhart, Y. B., AND P. Feinsinger. 1980. Plant-hummingbird interactions: Effects of island size and degree of specialization on pollination. Journal of Ecology 68: 745-760.

Louchart, A., N. Tourment, J. Carrier, T. Roux, and C. MourerCHauviré. 2008. Hummingbird with modern feathering: An exceptionally well-preserved Oligocene fossil from southern France. Die Naturwissenschaften 95: 171-175.

MacArthur, R. H., J. M. Diamond, and J. R. Karr. 1972. Density compensation in island faunas. Ecology 53: 330-342.

Martín, A., And J. A. Lorenzo. 2001. Aves del Archipiélago Canario. Francisco Lemus, La Laguna, Spain.

Marzol-JaÉn, M. V. 1984. El clima. In L. Afonso [ed.], Geografía de Canarias. Interinsular Canaria, Santa Cruz de Tenerife, Spain.

MAYr, G. 2004. Old World fossil record of modern-type hummingbirds. Science 304: 861-864.

Olesen, J. M. 1985. The Macaronesian bird-flower element and its relation to bird and bee opportunists. Botanical Journal of the Linnean Society 91: 395-414.

Olesen, J. M., And P. Jordano. 2002. Geographic patterns in plant-pollinator mutualistic networks. Ecology 83: 2416-2424.

Olesen, J. M., AND A. VAlido. 2003a. Lizards as pollinators and seed dispersers: An island phenomenon. Trends in Ecology \& Evolution 18: $177-181$

Olesen, J. M., AND A. VALido. 2003b. Bird pollination in Madeira Island. Ardeola 50: 67-69.

Olesen, J. M., AND A. VAlido. 2004. Lizards and birds as generalized pollinators and seed dispersers of island plants. In J. M. FernándezPalacios and C. Morici [ed.], Ecología insular/Island ecology, 229249. Asociación Española de Ecología Terrestre (AEET) - Cabildo Insular de La Palma, Santa Cruz de la Palma, Spain.

Ollerton, J., AND A. LACK. 1998. Relationships between flowering phenology, plant size and reproductive success in Lotus corniculatus (Fabaceae). Plant Ecology 139: 35-47.

PÉrez de PAZ, J., AND A. Roca. 1982. Estudio palinológico preliminar del género macaronésico Isoplexis Lindl. (Scrophulariaceae) y la sección Frutescentes Benth. de Digitalis L. Botánica Macaronésica 10: 93-114.

Philipp, M., J. Böcher, H. R. Siegismund, and L. R. Nielsen. 2006. Structure of a plant-pollinator network on a pahoehoe lava desert of the Galápagos Islands. Ecography 29: 531-540.

Price, M. V., AND N. M. Waser. 1982. Experimental studies of pollen carryover: Hummingbirds and Ipomopsis aggregata. Oecologia 54: 353-358.
Proctor, M., P. Yeo, AND A. LACK. 1996. The natural history of pollination. Timber Press, Portland, Oregon, USA.

Ricklefs, R. E., AND G. L. Miller. 1999. Ecology, 4th ed. Freeman, New York, New York, USA.

Rodda, G. H., AND K. Dean-Bradley. 2002. Excess density compensation of island herpetofaunal assemblages. Journal of Biogeography 29: 623-632.

SaKai, H. F., C. J. Ralph, and C. D. Jenkins. 1986. Foraging ecology of the hawaiian crow, an endangered generalist. Condor 88: 211-219.

Scott, S. N., S. M. Clegg, S. P. Blomberg, J. KikKawa, and I. P. F. Owens. 2003. Morphological shifts in island-dwelling birds: The roles of generalist foraging and niche expansion. Evolution 57: $2147-2156$

Sletvold, N. 2002. Effects of plant size on reproductive output and offspring performance in the facultative biennial Digitalis purpurea. Journal of Ecology 90: 958-966.

SoKaL, R. R., AND F. J. RoHLF. 1995. Biometry: The principles and practice of statistics in biological research. Freeman, New York, New York, USA.

Terborgh, J., AND J. FAABORg. 1973. Turnover and ecological release in avifauna of Mona Island, Puerto Rico. Auk 90: 759-779.

Thomson, J. D., M. V. Price, N. M. Waser, and D. A. Stratton. 1986. Comparative studies of pollen and fluorescent dye transport by bumble bees visiting Erythronium grandiflorum. Oecologia 69: 561-566.

Traveset, A., and E. Sáez. 1997. Pollination of Euphorbia dendroides by lizards and insects: A spatio-temporal variation in patterns of flower visitation. Oecologia 111: 241-248.

Valido, A., AND J. D. Delgado. 1996. Estudio sobre la comunidad de aves de la laurisilva en la isla de Tenerife. Seo/BirdLife, Madrid, Spain [unpublished report].

Valido, A., Y. L. Dupont, And D. M. Hansen. 2002. Native birds and insects, and introduced honey bees visiting Echium wildpretii (Boraginaceae) in the Canary Islands. Acta Oecologica 23: 413-419.

Valido, A., Y. L. Dupont, and J. M. Olesen. 2004. Bird-flower interactions in the Macaronesian islands. Journal of Biogeography 31: 1945-1953.

Vogel, S.,C.Westerkamp, B. Thiel, and K. Gessner. 1984. Ornithophilie auf den Canarischen Inseln. Plant Systematics and Evolution 146: $225-248$.

Werner, T. K., AND T. W. SHERry. 1987. Behavioral feeding specialization in Pinaroloxias inornata, the "Darwin's finch" of Cocos Island, Costa Rica. Proceedings of the National Academy of Sciences, USA 84: 5506-5510.

Whitaker, A. H. 1987. The roles of lizards in New Zealand plant reproductive strategies. New Zealand Journal of Botany 25: 315-328.

Wright, S. J. 1980. Density compensation in island avifaunas. Oecologia 45: 385-389. 